\title{
Investigating the Factors Influencing the Participation in Ride- Sharing: The Case of the Philippines
}

\author{
Laiza Limpin ${ }^{1,2+}$ \\ ${ }^{1}$ College of Computer Studies, De La Salle University, 2401 Taft Ave., Malate, Manila, Philippines \\ ${ }^{2}$ Mindanao State University - General Santos City, Brgy. Fatima, General Santos City, Philippines
}

\begin{abstract}
The sharing economy, which leverages information and communication technologies (ICT) for the sharing of assets and services, has made significant inroads in ASEAN countries, including the Philippines, which in 2015 became the first country to create and implement a regulatory framework for ridesharing through transportation network company (TNC) apps like Uber. However, despite its growing practical importance and wide acceptance in the country, there is a gap in the literature which focuses on motivational factors influencing the participation in sharing activities. Therefore, this paper employs a quantitative approach to investigate the people's motivation to engage in ride-sharing in the Philippine setting. The result of an online survey which gathered 215 responses from registered Uber users showed that people's attitude towards ride-sharing activities are positively influenced by some factors such as enjoyment, sustainability, reputation and economic benefits. However, the result also reveals that a positive attitude influenced by reputation and sustainability does not guarantee actual participation in ride-sharing. Moreover, people who have a positive perception towards ride-sharing may find themselves using the service. Further studies and implications on the improvement of ride-sharing services are discussed.
\end{abstract}

Keywords: sharing economy, ride-sharing, Uber, motivation, ICT, internet technologies

\section{Introduction}

The attitude towards consumption has changed in the recent years as the ecological, societal and developmental effects [1] of modern economy have become more evident making the sharing economy an appealing alternative to traditional consumption. The sharing economy, sometimes referred to as peer-to-peer economy or collaborative consumption, involves sharing of assets and services with the help of information and communications technologies (ICT), particularly Internet applications that match asset owners with those whom they might want to share these assets with, whether for a fee or not. Because these assets and services are typically underutilized unless shared, the sharing economy, therefore, enables their greater if not maximal utilization.

While its widespread adoption remains to be seen, the sharing economy has unquestionably penetrated some industries including transportation, accommodation, and services. In the transportation sector, ridesharing allows an individual to co-use a vehicle for a trip which is arranged through a transportation network company (TNC) applications like Uber, thereby sharing the costs with the owner. Ride-sharing has been argued to benefit the participants, the society, and the environment by saving travel cost and time, ease traffic congestion, conservation of fuel and reduction of air pollution [2].

Established in San Francisco, California in 2009, Uber has, as of this writing, expanded to more than 760 cities in 84 countries (https://uberestimator.com/cities). Uber was officially launched in Metro Manila, Philippines in February 2014, after a quiet and unofficial launch in December 2013 [3]. In May 2015, the Philippines became the first country to develop nationwide regulations for app-based car-hailing operations

\footnotetext{
+ Corresponding author. Tel: No: (083) 8782594

Email Address: laiza_limpin@dlsu.edu.ph
} 
which allowed Uber and similar-app based hailing services to operate legally anywhere in the country [4]. In October 2015, there were 3,499 applicants for transport network vehicle services (TNVS) [5]. Less than a year later, in September 2016, 27,062 applications were submitted [6].

However, despite its growing popularity and practical importance in the country, factors influencing Filipinos' participation in ride-sharing are yet to be investigated. Therefore, employing a quantitative approach, this paper intends to fill this gap as its contribution to research. It further explores attitude and behavioral intentions towards ride-sharing services in the Philippines.

\section{Review of Related Literature}

The sharing economy has expanded rapidly and includes a variety of services including ride-sharing, accommodation sharing, car-sharing, services, etc. It leverages on Internet technologies to match providers who own resources and users who need these resources but do not want to actually own them [7]. In particular, ride-sharing is a mode of transportation which enables individuals to share a vehicle for a trip and split travel costs [8]. It benefits customers, drivers and the society [9]. In 2017, 8.3\% of the total global population aged 16 years and older were active paying customers and is expected to reach at $13 \%$ by 2022 [10].

As the sharing economy becomes widespread, several studies focusing on exploring the motivations influencing participation have been conducted [1], [11], [12], [13], [14]. However, many of these researches are exploratory in nature and yet to be tested quantitatively to support its applicability and generalizability. In addition, despite its legalization and widespread acceptance in the Philippines, there is a lack of literature that investigates the antecedents of participation in the sharing economy in the country.

\section{Theoretical Framework}

The theoretical framework as shown in Fig. 1 was adopted from a study [1] to test the applicability of the model to the Philippine setting.

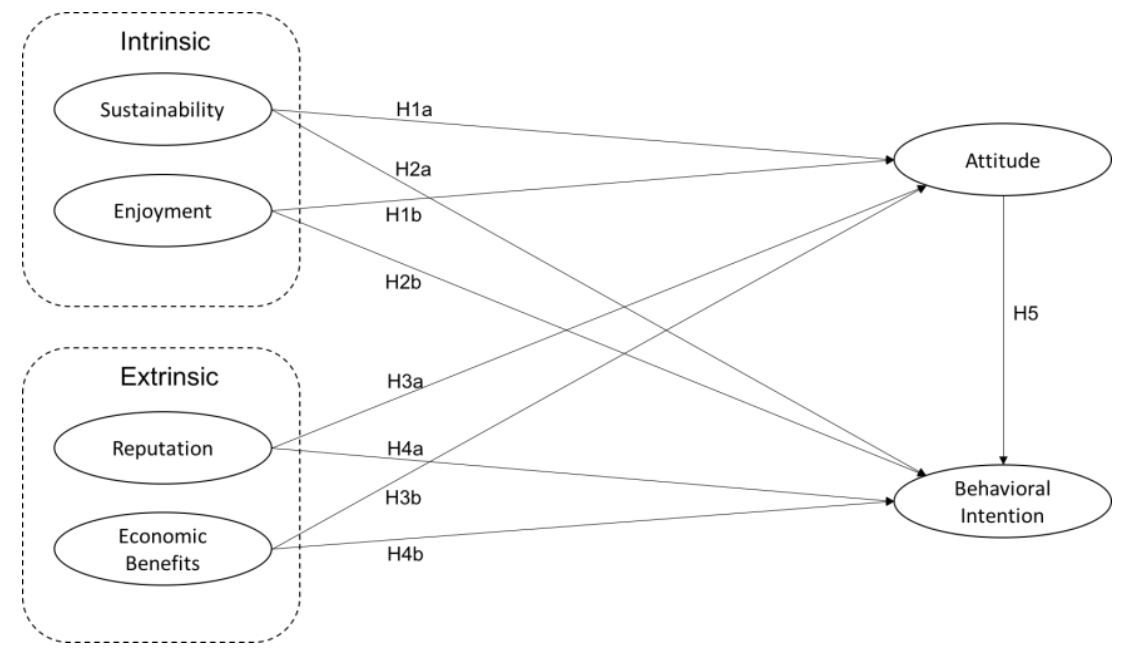

Fig. 1: Theoretical framework.

The hypothesis of the study was developed based on four motivational categories: sustainability, enjoyment, reputation and economic benefits. These categories were grounded on the self-determination theory [15] which posits that motivations can be classified as intrinsic and extrinsic.

The intrinsic motivations identified for this study include sustainability and enjoyment. Sustainability is the idea that sharing is environment-friendly [1]. In addition, the sharing economy is seen to promote social and economic sustainability [16]. Through this study, we gain an understanding as to why people choose to invest their time and energy in sharing activities that may benefit wider social, economic and environmental sustainability. On the other hand, enjoyment is the idea that sharing has a value to help others [17]. Specifically, enjoyment is a significant intrinsic benefit for online sharing behavior [1] and provides users a 
sense of novelty and authentic experience [18]. It is assumed that enjoyment plays a key role in influencing participation in sharing behavior.

While participants of the sharing economy are intrinsically motivated by benefits such as enjoyment and sustainability, some are extrinsically motivated by external rewards such as reputation and economic rewards. The sharing economy has been an appealing alternative to many consumers as it affords them monetary benefits [11], [19]. The sharing economy allowed the sharing of underutilized resources allowing greater utilization and consequently, goods and services are available at lower prices encouraging user participation [20]. Economic benefits can be in a form of saving money and time. Moreover, reputation has been shown to be an important external motivational factor for sharing behavior [1], [14], [21]. Many sharing economy platforms have built an online reputation system that enables and encourages participates to review and rate each completed transaction [22].

\section{Methodology}

The study aims to understand the adoption of the sharing economy in the Philippines by investigating the factors that motivate people to engage in ride-sharing services.

An online questionnaire was deployed through Google Forms to gather data for the study. The study adopted the instrument used in [1] and after analysis and validation, minor changes were made to fit the ridesharing context in the Philippine setting. The questionnaire consisted of 22 questions pertaining to the categories identified in the theoretical model: sustainability (5), enjoyment (4), reputation (4), economic benefits (2), attitude (4) and behavioral intentions (3). All items used a 7-point Likert scale ranging from $1=$ "strongly disagree" to 7 = "strongly agree".

A total of 215 valid responses from registered Uber users were gathered and analyzed. Uber is a ridesharing platform that allows its partners (drivers) to use their own vehicle to pick up riders and drive them to their preferred destination in exchange for a fee. Of 215 respondents, there was 133 Male (62\%), 82 Female (38\%). The majority were in the age group 25-34 years old (46\%). In terms of income, $30 \%$ answered that they earn between Php 25,000 - Php 40,000.

\section{Results and Discussions}

\subsection{Instrument Validation through Factor Analysis}

The instrument used in the study was validated using a Partial Least Squares algorithm. Partial Least Squares - Structural Model (PLS-SEM) is a second-generation multivariate statistical application used in various fields of study such as psychology and marketing. It has been proven to be effective for studies with a limited sample size such as in [23].

The first ten (10) responses of the survey were validated using the SmartPLS 3.2.7 statistical tool. The initial result of the validation test showed that the attitude and economic benefits constructs are below the Cronbach's Alpha critical level of $0.70(\alpha<0.70)$. The indicators for above-mentioned constructs were reviewed and results revealed that Questions 1 and Questions 3 for the economic benefits construct were below the acceptable value, having - 0.573 and -0.644 respectively. Additionally, Question 5 for the attitude construct yielded a value of -0.143 . These indicators were deleted individually applying the PLS algorithm for each deletion. The result of the validity and reliability test using the PLS algorithm is shown in Table 2.

Table 1: Result of the validity and reliability test using PLS algorithm

\begin{tabular}{|l|c|c|c|}
\hline \multicolumn{1}{|c|}{ Constructs } & Cronbach's Alpha & $\begin{array}{c}\text { Composite } \\
\text { Reliability }\end{array}$ & $\begin{array}{c}\text { Average Variance } \\
\text { Extracted (AVE) }\end{array}$ \\
\hline Attitude & 0.877 & 0.901 & 0.731 \\
\hline Behavioral Intent & 0.923 & 0.929 & 0.866 \\
\hline Sustainability & 0.956 & 0.966 & 0.849 \\
\hline Enjoyment & 0.930 & 0.957 & 0.828 \\
\hline Reputation & 0.957 & 0.961 & 0.884 \\
\hline Economic Benefits & 0.935 & 0.935 & 0.799 \\
\hline
\end{tabular}




\subsection{Validation of the Model Using PLS-SEM}

To validate the model, a complete bootstrapping technique with 5,000 sample and 1-tailed significance level of 0.05 was applied. The result of the statistical test is shown in Table 2.

Table 2: Model evaluation results using PLS-SEM

\begin{tabular}{|c|l|c|c|c|c|}
\hline Hypothesis & \multicolumn{1}{|c|}{ Relationship } & $\begin{array}{c}\text { Path } \\
\text { Coefficient }\end{array}$ & T-Statistics & $\begin{array}{c}\text { Significance } \\
\text { Level }\end{array}$ & Results \\
\hline H1a & Sustainability -> Attitude & 0.179 & 2.174 & 0.05 & Accepted \\
\hline H1b & Sustainability -> Behavioral Intention & -0.006 & 0.118 & NS & Rejected \\
\hline H2a & Enjoyment -> Attitude & 0.499 & 7.042 & 0.01 & Accepted \\
\hline H2b & Enjoyment -> Behavioral Intention & 0.409 & 5.566 & 0.01 & Accepted \\
\hline H3a & Reputation -> Attitude & -0.251 & 3.227 & 0.01 & Accepted \\
\hline H3b & Reputation -> Behavioral Intention & 0.067 & 1.028 & NS & Rejected \\
\hline H4a & Economic Benefits - Attitude & 0.338 & 4.135 & 0.01 & Accepted \\
\hline H4b & Economic Benefits -> Behavioral Intention & 0.125 & 1.962 & 0.05 & Accepted \\
\hline H5 & Attitude -> Behavioral Intention & 0.396 & 6.281 & 0.01 & Accepted \\
\hline
\end{tabular}

In case of the intrinsic motivations, the result shows that sustainability positively influences attitude (H1a $\mathrm{t}=2.174)$; however, it is not directly associated with behavioral intentions $(\mathrm{H} 1 \mathrm{~b} \mathrm{t}=0.018)$ towards ridesharing. Perceived enjoyment, on the other hand, had a significant positive effect on both the participants' attitude $(\mathrm{H} 2 \mathrm{at}=7.042)$ and intention $(\mathrm{H} 2 \mathrm{~b} \mathrm{t}=5.566)$ to engage in ride-sharing activities.

In the case of extrinsic motivations, reputation positively influences participants' attitude $(\mathrm{H} 3 \mathrm{a} t=3.227)$ however, it does not have a significant effect on their intention $(\mathrm{H} 3 \mathrm{~b} \mathrm{t}=1.028)$ to use ride-sharing services. On the other hand, perceived monetary gains have been found to positively influence participants' attitude $(\mathrm{H} 4 \mathrm{a} \mathrm{t}=4.135)$ and intentions $(\mathrm{H} 5 \mathrm{~b} \mathrm{t}=1.962)$ towards ride-sharing. Finally, the result of the test reveals that attitude has a significant positive effect on the participants' behavioral intentions $(\mathrm{H} 5 \mathrm{t}=6.281)$ towards ride-sharing.

\section{Conclusion and Recommendations}

In conclusion, this study focuses on the intrinsic and extrinsic motivations that influence the participants' attitude and intention towards ride-sharing services. The result of the study reveals that both intrinsic and extrinsic motivations are antecedent of attitude towards ride-sharing. However, this is in contrast with [1] who rejected the hypothesis that extrinsic motivation is a determinant of attitude. The disparity in the result may be brought about by the cultural differences of the participants from both studies. Moreover, the lack of adequate mass transport [24] may have contributed to the increasing acceptability of ride-sharing services in the country.

The findings of the study also revealed that people may perceive ride-sharing as a sustainable way of traveling, however, it does not always result in actual usage of the service. Factors such as economic rationalizations, institutional dependencies, and developmental realism have been found to deter consumers from sustainable consumption [25]. While ride-sharing has been seen to promote a green image, its true impact on the environment has not been thoroughly investigated. There is yet adequate evidence in the literature which shows that ride-sharing will reduce private car ownership, energy consumption and greenhouse emissions [26].

Moreover, reputation has been found to positively influence participants' attitude towards ride-sharing but this does not always translate into action. This finding implies that ride-sharing participants does not engage in such activities in order to gain a higher status in the community which is in contrast with other collaborative platforms such as Wikipedia [27].

This study contributes to the extant literature about the adoption of the sharing economy specifically in the context of ride-sharing. Moreover, it provides the applicability of the theoretical model developed by Hamari, et al [1] and contributes context as to why Filipinos engage in ride-sharing activities. In addition, the findings of this study may have implications towards the improvement of ride-sharing services in the country. Providers of ride-sharing services should focus on making the service engaging and pleasurable as enjoyment has been found to be one of the motivational factors in participation. Additionally, transport 
network companies such as Uber may improve their marketing strategies to entice more riders or Uber drivers may provide freebies or some entertainment to make the ride more enjoyable.

This study focuses on examining the factors that influence participants to adopt ride-sharing services. It is, therefore, recommended that further studies should explore the relationship between the participants' intention to use and actual behaviors.

\section{Acknowledgement}

The author would like to express her gratitude to everyone involved in writing this research. Appreciation goes to the participants of this study for without them, this research will not be possible. The author would also like to express her gratitude to the Office of the Vice Chancellor for Research and Innovation (VCRI) of De La Salle University - Manila for the generous support in the publication of this research. In addition, the author would like to acknowledge her friends and classmates from De La Salle University for always supporting and encouraging her to complete this study.

\section{References}

[1] J. Hamari, M. Sjoklint, and A. Ukkonen, "The sharing economy: Why people participate in collaborative consumption," J. Assoc. Inf. Sci. Technol., vol. 67, no. 9, pp. 2047-2059, 2016.

[2] S. Wallsten, "The Competitive Effects of the Sharing Economy : How is Uber Changing Taxis ?," New York, 2015.

[3] P. Magdirilia, "Uber officially launching in Manila," 2014. [Online]. Available: https://www.techinasia.com/uberofficial-manila-expect-costs-payment-options.

[4] S. Toppa, "Uber Is Now Legal Everywhere in the Philippines | TIME," Time, 2015. [Online]. Available: http://time.com/3854958/uber-legal-philippines-ride-hailing/.

[5] E. Sauler, "LTFRB exec: Suspend franchise applications for app-based vehicles | Inquirer News," Philippine Daily Inquirer, 2015.

[6] L. Marasigan, "Uber: Ride share can help decongest worsening traffic in Metro Manila | BusinessMirror," Business Mirror, 2016.

[7] M. Matzner, F. Chasin, and L. Todenhöfer, "To Share or Not to Share: Towards Understanding the Antecedents of Participation in IT-Enabled Sharing Services," 2015.

[8] M. Furuhata, M. Dessouky, F. Ordóñez, M.-E. Brunet, X. Wang, and S. Koenig, "Ridesharing: the State-of-the-art and Future Directions," 2013.

[9] M. Böckmann, "The Shared Economy: It is time to start caring about sharing; value creating factors in the shared economy," University of Twente, 2013.

[10] P. T. Giang, P. T. Trang, and V. T. Yen, "An Examination of Factors Influencing the Intention to Adopt Ride-Sharing Applications : A Case Study in Vietnam,” no. 10, pp. 618-623, 2017.

[11] I. P. Tussyadiah, "An Exploratory Study on Drivers and Deterrents of Collaborative Consumption in Travel," in Information and Communication Technologies in Tourism 2015, Springer, 2015.

[12] F. Hawlitschek, T. Teubner, and H. Gimpel, "Understanding the Sharing Economy - Drivers and Impediments for Participation in Peer-to-Peer Rental Understanding the Sharing Economy - Drivers and Impediments for Participation in Peer-to-Peer Rental," in Hawaii International Conference on System Sciences (HICSS), 2016.

[13] I. Ballús-Armet, S. A. Shaheen, K. Clonts, and D. Weinzimmer, "Peer-to-Peer Carsharing: Exploring Public Perception and Market Characteristics in the San Francisco Bay Area, California," Transp. Res. Rec. J. Transp. Res. Board, no. 2416, pp. 27-36, 2014.

[14] S. Yang and S. Ahn, "Impact of Motivation in the Sharing Economy and Perceived Security in Attitude and Loyalty toward Airbnb," Adv. Sci. Technol. Lett., vol. 129, pp. 180-184, 2016.

[15] R. M. Ryan, G. C. Williams, H. Patrick, and E. L. Deci, "Self-determination theory and physical activity: the dynamics of motivation in development and wellness," Hellenic Journal of Psychology, vol. 6. pp. 107-124, 2009.

[16] X. Wu and Q. Zhi, "Impact of Shared Economy on Urban Sustainability: From the Perspective of Social, Economic, and Environmental Sustainability,” Energy Procedia, vol. 104, pp. 191-196, 2016. 
[17] A. Kankanhalli, B. C. Y. Tan, and K. Wei, "Contributing knowledge to electronic knowledge repositories: An empirical investigation,” MIS Q., vol. 29, no. 1, pp. 113-143, 2005.

[18] E. Mcarthur, "Many-to-many exchange without money: why people share their resources," Consumption, vol. 18, no. 3, p. 239, 2015.

[19] S. J. Barnes and J. Mattsson, "Understanding current and future issues in collaborative consumption: A four-stage Delphi study," 2016.

[20] Z. W. Y. Lee, T. K. H. Chan, M. S. Balaji, A. Yee, and -Loong Chong, "Technology-mediated Sharing Economy: Understanding User Participation in Collaborative Consumption Through the Benefit- Cost Perspective," in 20th Pacific Asia Conference on Information Systems, 2016.

[21] E. Ert, A. Fleischer, and N. Magen, Trust and reputation in the sharing economy: The role of personal photos in Airbnb, vol. 55, no. August. 2016.

[22] G. Zervas, D. Proserpio, and J. W. Byers, "The Rise of the Sharing Economy: Estimating the Impact of Airbnb on the Hotel Industry,” SSRN Electron. J., 2016.

[23] R. Ebardo, "The use of activity trackers for health empowerment and commitment: the Philippine cycling perspective commitment : the Philippine cycling perspective "," 7th Int. Work. Comput. Sci. Eng. (WCSE 2017), no. April, pp. 2527, 2017.

[24] N. J. Morales, "Philippines issues rules on ride-sharing services, as taxis threaten court | Reuters," Reuters, 2015. [Online]. Available: http://www.reuters.com/article/us-philippines-uber-idUSKBNONY15Y20150513.

[25] G. Eckhardt, R. Belk, and T. Devinney, "Why Don’t Consumers Consumer Ethically,” J. Consum. Behav., vol. 9, no. 6, pp. 426-436, 2010.

[26] S. T. Jin, H. Kong, R. Wu, and D. Z. Sui, "Ridesourcing, the sharing economy, and the future of cities," Cities, no. October 2017, pp. 0-1, 2018.

[27] D. Anthony, S. W. SMith, and T. Williamson, "Reputation and reliability in collective goods the case of the online encyclopedia Wikipedia.,” Ration. Soc., vol. 21, no. 3, pp. 283-306, 2009. 